\title{
Epidemiology of lung cancer and approaches for its prediction: a systematic review and analysis
}

\author{
Ashutosh Kumar Dubey*, Umesh Gupta and Sonal Jain
}

\begin{abstract}
Background: Owing to the use of tobacco and the consumption of alcohol and adulterated food, worldwide cancer incidence is increasing at an alarming and frightening rate. Since the last decade of the twentieth century, lung cancer has been the most common cancer type. This study aimed to determine the global status of lung cancer and to evaluate the use of computational methods in the early detection of lung cancer.

Methods: We used lung cancer data from the United Kingdom (UK), the United States (US), India, and Egypt. For statistical analysis, we used incidence and mortality as well as survival rates to better understand the critical state of lung cancer.

Results: In the UK and the US, we found a significant decrease in lung cancer mortalities in the period of 1990-2014, whereas, in India and Egypt, such a decrease was not much promising. Additionally, we observed that, in the UK and the US, the survival rates of women with lung cancer were higher than those of men. We observed that the data mining and evolutionary algorithms were efficient in lung cancer detection.

Conclusions: Our findings provide an inclusive understanding of the incidences, mortalities, and survival rates of lung cancer in the UK, the US, India, and Egypt. The combined use of data mining and evolutionary algorithm can be efficient in lung cancer detection.
\end{abstract}

Keywords: Lung cancer, Incidence and mortality rates, Data mining, Evolutionary algorithms

\section{Background}

Worldwide, lung cancer is the leading cause of cancerrelated death. However, according to the latest medical research reports [1-3], if the nature and symptoms of cancer are correctly identified at an early stage, it can be cured. The cancer spreads to other parts of the body through the blood and lymphatic system, which is a process called metastasis, and then quickly causes the development of secondary tumors [4]. Some high-risk factors like smoking, breathing polluted air, and living in a polluted area can negatively affect the prognosis and quality of life of lung cancer patients $[1,5]$. Lung cancer can also be hereditary [2].

*Correspondence: ashutoshdubey123@gmail.com

Institute of Engineering and Technology, JK Lakshmipat University, Near Mahindra SEZ, P.O. Mahapura, Ajmer Road, Jaipur, Rajasthan 302 026, India
At the beginning of the twentieth century, the incidence of lung cancer was very low, but now its incidence is increasing rapidly $[4,6]$. According to the GLOBOCAN 2012 report, there have been 1.8 million new cases (incidence) of lung cancer globally, constituting $12.9 \%$ of the total estimated cancer incidence in the year 2012 [2]. Of these cases, $58.0 \%$ are from the underdeveloped countries [2]. Hungary had the highest incidence of lung cancer $(51.6 \%)$, followed by Serbia (45.6\%) and Korea (44.2\%) [2]. In 2012, lung cancer incidences for both men and women were highest in North America; the incidences were lowest in Africa, followed by Latin America and the Caribbean. In the same year, incidence of lung cancer in men was highest in Hungary (76.6\%), followed by Armenia (72.9\%) and Macedonia (44.2\%) [2]. In India, the lung cancer mortality is high [7]. In 2012, the World Health Organization (WHO) reported that, worldwide, lung 
cancer causes 1.59 million deaths [8]. Tobacco-smokers aged above 50 years are at the highest risk for lung cancer. Presently, incidence of lung cancer is low in women, but changes in lifestyle might increase it in the future.

Based on the aforementioned data, it is clear that the worldwide incidence of lung cancer is alarming; indeed, it has become the most common and fatal type of cancer. The main objectives of this study were to assess the incidence of lung cancer and the associated mortality, and to analyze the on-going research in the field of computational methods for lung cancer detection. An in-depth analysis of the current research will be helpful in the development of new techniques to detect lung cancer at an early stage.

\section{Data sources and methods}

For this study, we collected data on lung cancer incidence and mortality in the United Kingdom (UK), the United States (US), India, and Egypt from the following sources [3]. We have also considered data sources from France and Switzerland, as these organizations collect and publish global data.

\section{UK}

General Register Office for Scotland: A repository that maintains medical statistics and records of births and deaths.

Information Services Division (ISD), Scotland: Part of National Services Scotland. Provides health data to all, free of charge.

National Cancer Intelligence Network (NCIN): Established to improve clinical outcomes, cancer care, and prevention. Since April 2013, part of Public Health England.

Northern Ireland Cancer Registry: Established in 1994 and located in the Centre for Public Health, Queen's University Belfast. Maintains cancer incidence and mortality data. Funded by the Public Health Agency for Northern Ireland.

Northern Ireland Statistics and Research Agency: A repository that maintains medical data and social research as well as records of deaths and births.

Office for National Statistics (ONS): A statistical institute of the UK. Collects and publishes population, social, and economic statistics.

United Kingdom and Ireland Association of Cancer Registries (UKIACR): Focuses on developing cancer registration in the UK and Ireland for the purpose of studying and controlling cancer.

Welsh Cancer Intelligence and Surveillance Unit (WCISU), Wales: The national cancer registry of Wales. Stores and publishes data on cancer incidences in Wales.
US

Centers for Disease Control and Prevention (CDC): It helps in detecting and responding to new and emerging health threats. The aim of CDC is to tackle the biggest health problems that cause disability and death.

Surveillance, Epidemiology, and End Results (SEER) database: An authoritative source of information on cancer incidence and survival in the US.

\section{India}

Indian Cancer Society (ICS): A non-profit organization established by Dr. Darab Jehangir Jussawalla and Mr. Naval Tata for cancer awareness, detection, cure, and survival. Also gathers cancer-related incidence and mortality data from different cities in India.

Indian Council of Medical Research (ICMR): A council in New Delhi, India, for the preparation, collocation, and support of biomedical research. Main research focus is to control communicable diseases, cancer, cardiovascular diseases, blindness, and diabetes and to develop healthcare strategies. Launched the National Cancer Registry Program (NCRP) to collect reliable cancer data, conduct epidemiologic studies, design cancer control strategies, and organize cancer awareness programs.

Institute of Cytology and Preventive Oncology (ICPO): It is a leading institute under the ICMR. It provides awareness, prevention strategies, and treatments of leading cancers in India.

\section{Egypt}

Gharbiah Population-based Cancer Registry (GPCR): Sponsored by the Middle East Cancer Consortium and the Egyptian Ministry of Health. Publishes annual statistics of cancer incidence and mortality as well as possible control strategies.

International Association of Cancer Registries (IACR): A professional society that collects cancer-related incidence, mortality, and survivorship data for a specific population group.

National Cancer Registry Program of Egypt (NCRP): Supported by the Egyptian Ministry of Communications and Information Technology. Collects cancer data, conducts data analysis, operates training programs, and develops cancer control strategies.

\section{Other countries}

World Health Organization (WHO), Switzerland: Established in 1948 in Geneva, Switzerland. Part of the United Nations. Dedicated to all matters of global health.

International Agency for Research on Cancer (IARC), France: A specialized cancer research agency of the WHO. Develops and enhances cancer prevention 
measures, identifies malignancies at the earliest possible stage, and publishes periodic reports on cancer incidence.

GLOBOCAN 2014, France: A project of the IARC and the WHO. Estimates cancer incidence, mortality, and prevalence at the national level for 184 countries.

Systematic procedures and methods, surveys, and existing studies yield epidemiologic indicators that are capable of showing the process and the outcomes of a disease. Based purely on calculations and numerical information, quantitative indicators or methods can be useful. Useful quantitative indicators include incidence, prevalence, and mortality. Incidence measures new cases of lung cancer in the present population, whereas mortality is the estimate of deaths due to lung cancer in the total population $[9,10]$. In this study, we used incidence and mortality to elucidate the effects of lung cancer on the population.

Incidence was calculated by using the formula as follows $[2,9,10]$ :

Incidence $=(\mathrm{LCCCP} / \mathrm{TPRCP}) \times 10^{\mathrm{N}}$

$\mathrm{LCCCP}=$ Number of new lung cancer cases in the current period

TPRCP $=$ Number of total population at risk in the current period

$\mathrm{N}=1,2,3 \ldots$ [Sample population]

Mortality was calculated using the formula $[2,9,10]$ :

Mortality $=(\mathrm{DCCP} / \mathrm{TPCP}) \times 10^{\mathrm{N}}$

$\mathrm{DCCP}=$ Number of death cases in the current period

TPCP $=$ Number of total population in the current period

$\mathrm{N}=1,2,3 \ldots$ [Sample population].

The current period means the years considered for the calculation of incidence and mortality.

Knowing the cancer survival rate in a given population enables researchers to estimate cancer trends and patterns as well as people's fitness levels. Net survival shows the probability of surviving cancer without considering death from other causes. Since net survival is not influenced by other causes, it gives reliable results [11]. Two general approaches were used to estimate net survival: specific survival and relative survival. Specific survival is calculated from causes of cancer deaths [11] and is used mainly for clinical trials. According to Parkin et al. [12], sometimes the cause of death may be unavailable or unreliable; in such a case, it is not possible to correctly estimate survival. However, survival from other diseases can be helpful in finding the survival status of the patient with the disease under study by finding the differences between the other diseases and the total occurrences. It can be calculated by relative survival [12].

Relative survival rate $=\frac{\text { Observed survival proportion }}{\text { Expected survival proportion }} \times 100 \%$
Expected survival can be calculated by Ederer I, Edere II, and Hakulinen methods. In this study, we used net survival and relative survival rates.

\section{Results}

\section{Lung cancer epidemiology in the UK}

We first considered the incidence and mortality of lung cancer in the UK during the period 1975-2014. These data were based on age-adjusted or age-standardized rates. Age-adjusted rates eliminate age bias, allowing reliability when different population groups are compared. Incidence and mortality varied between populations based on age, race, sex, and demographic factors. Therefore, we compared population groups of varying ages from different countries and cities.

Table 1 shows the lung cancer incidence and mortality in the UK during the years 1975-2014 [13-19]. Incidence and mortality were based on the European age-standardized rate per 100,000 people in the UK. For men, lung cancer incidence increased in 1975-1980 and gradually decreased during 1985-2014, whereas the mortality gradually decreased during 1975-2014. For women, lung cancer incidence and mortality moderately increased during 1975-2014. Many factors, such as age, genetics, pollution and radiation levels, and lifestyle, can affect the development of lung cancer [20-22]. In the UK, smoking was the principal cause of lung cancer; $86.0 \%$ of lung cancer cases were associated with smoking [23, 24].

Figures 1,2, 3 and 4 illustrate the survival rates of men and women with lung cancer in the UK during the period 1971-2011 [13, 14, 16, 17, 25, 26]. Figure 1 shows that the 1-year survival rate increased from $16.2 \%$ to $30.4 \%$ for men and from $15.4 \%$ to $35.1 \%$ for women. Figure 2 shows that, for men, the 5-year survival rate increased from $4.8 \%$ to $8.4 \%$ in the period 1971-2011; for women, the 5-year survival rate increased from $4.4 \%$ to $11.6 \%$ in the same

Table 1 Age-standardized rates of lung cancer incidence and mortality in the United Kingdom (1975-2014)

\begin{tabular}{llllll}
\hline Year & \multicolumn{2}{l}{$\begin{array}{l}\text { Incidence (per 100,000 } \\
\text { people) }\end{array}$} & & \multicolumn{2}{l}{$\begin{array}{l}\text { Mortality (per } \\
\mathbf{1 0 0 , 0 0 0} \text { people) }\end{array}$} \\
\cline { 2 - 3 } & Men & Women & & Men & Women \\
\hline 1975 & 111.9 & 22.6 & & 107.9 & 21.5 \\
1980 & 113.2 & 28.1 & & 106.6 & 25.6 \\
1985 & 109.8 & 33.3 & & 100.1 & 28.8 \\
1990 & 86.7 & 34.3 & & 87.7 & 30.5 \\
1995 & 81.4 & 35.3 & & 72.8 & 30.5 \\
2000 & 70.5 & 36.5 & & 60.5 & 29.8 \\
2005 & 63.0 & 38.0 & & 53.1 & 30.3 \\
2010 & 59.2 & 40.5 & & 48.0 & 31.4 \\
$2011-2014$ & 58.2 & 40.8 & & 47.3 & 31.1 \\
\hline
\end{tabular}




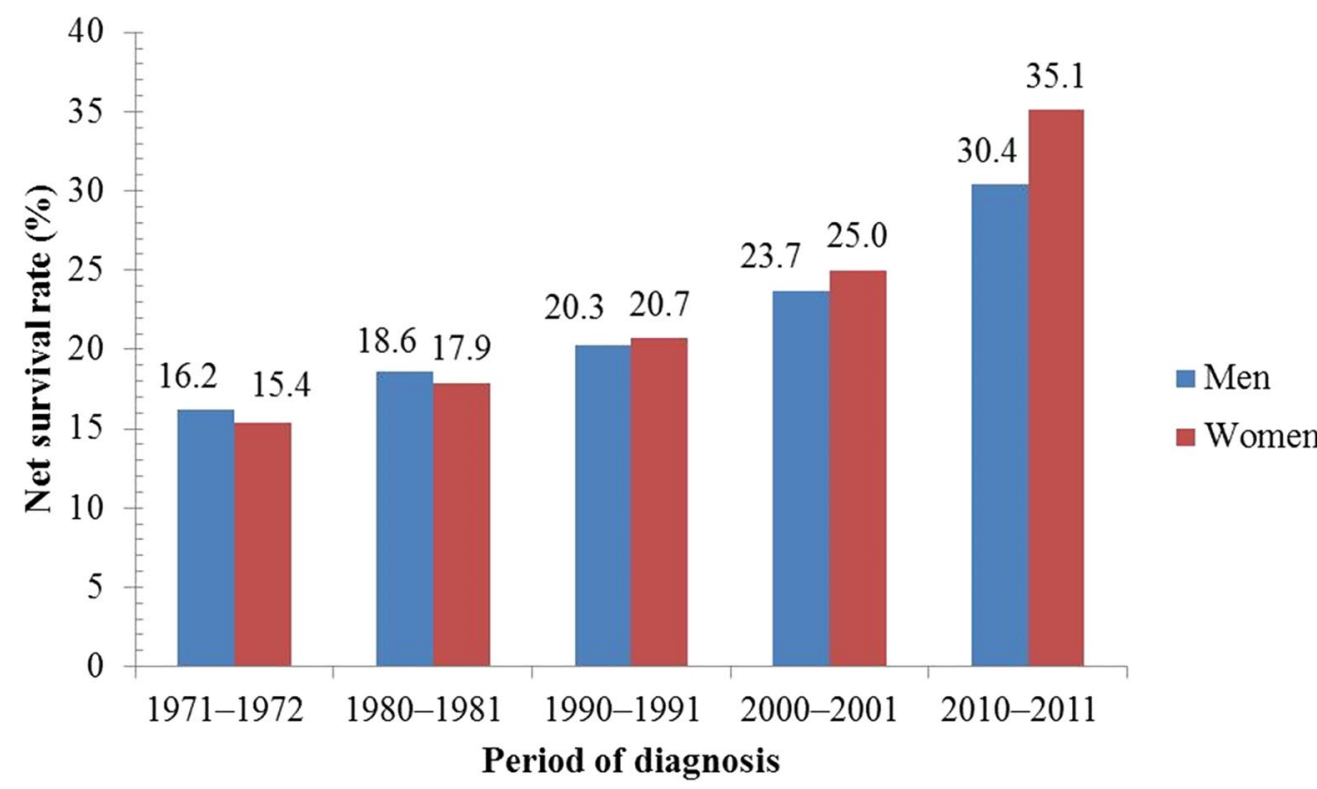

Fig. 1 One-year net survival trends of lung cancer patients in the United Kingdom (UK). During the period 1971-2011, the 1-year age-standardized (age 15-99 years) net survival rates of men with lung cancer increased from $16.2 \%$ to $30.4 \%$; for women, the survival rate increased from $15.4 \%$ to $35.1 \%$ during the same period

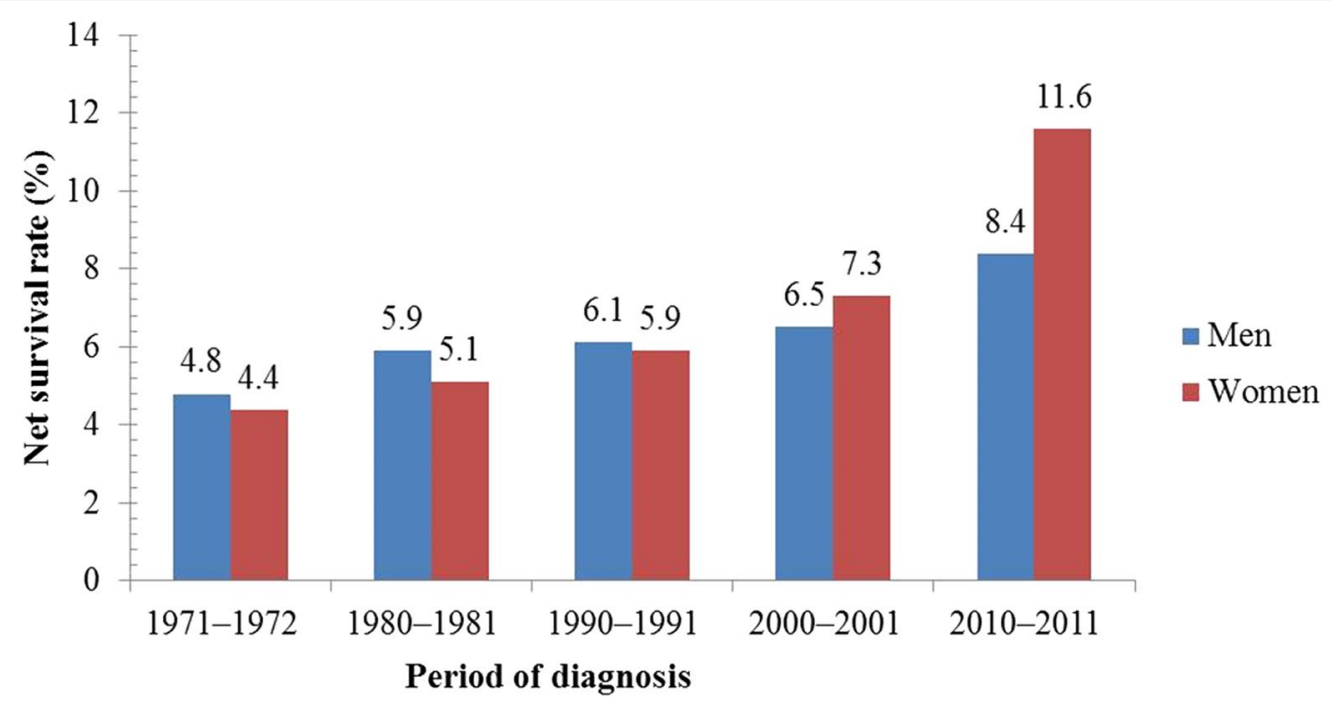

Fig. 2 Five-year net survival trends of lung cancer patients in the UK. During the period 1971-2011, the 5-year age-standardized (age 15-99 years) net survival rates of men with lung cancer has increased from $4.8 \%$ to $8.4 \%$; for women, the survival rate increased from $4.4 \%$ to $11.6 \%$ during the same period

period. Figure 3 shows that, for men and women in the UK with lung cancer, the 10-year survival rate increased from $3.2 \%$ to $4.0 \%$ and from $2.9 \%$ to $6.5 \%$, respectively, in the period 1971-2011. Figure 4 shows that, in the period 2007-2011, the survival rate of men and women in the UK with lung cancer gradually decreased from $38.4 \%$ to
$4.8 \%$ and from $45.0 \%$ to $5.0 \%$, respectively, with increasing age. Survival of lung cancer patients in the UK remained poor due to (i) late identification of symptoms, (ii) nonavailability of optimal treatment to most patients, (iii) lack of efficient screening programs, and (iv) co-occurrence with obesity and smoking $[27,28]$. 


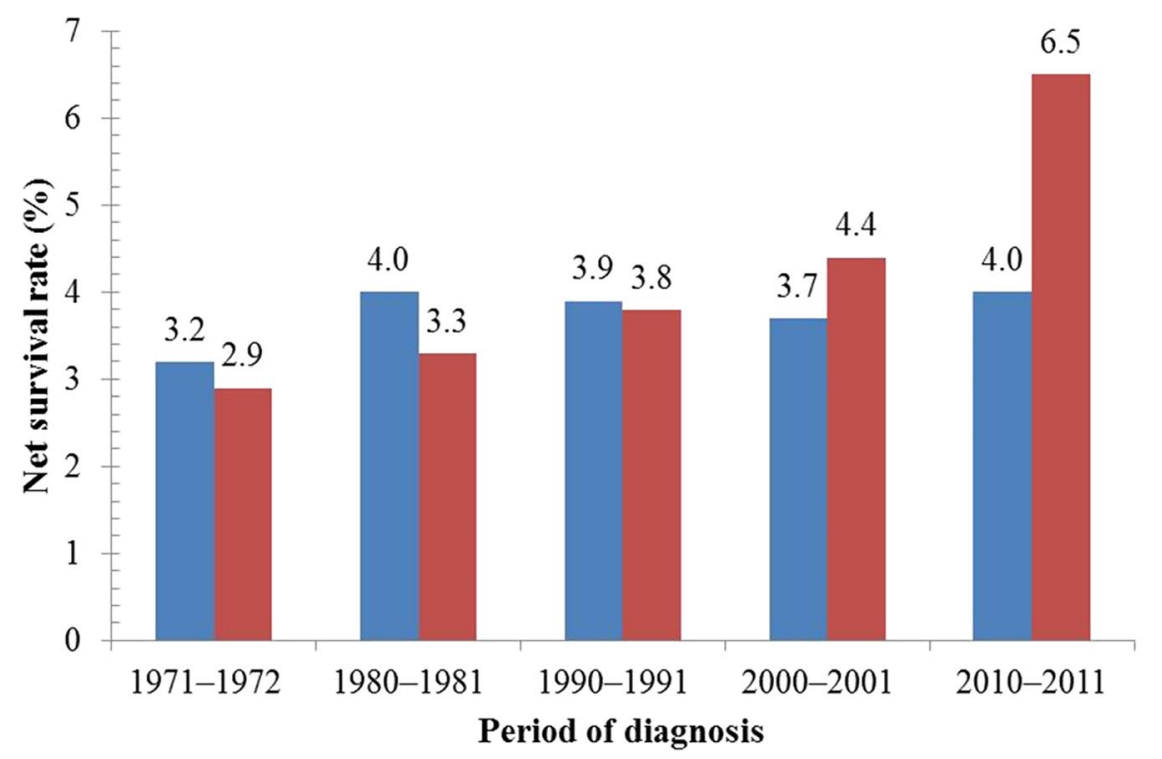

men

Women men with lung cancer increased from 3.2\% to 4.0\%; for women, the survival rate increased from $2.9 \%$ to $6.5 \%$ during the same period

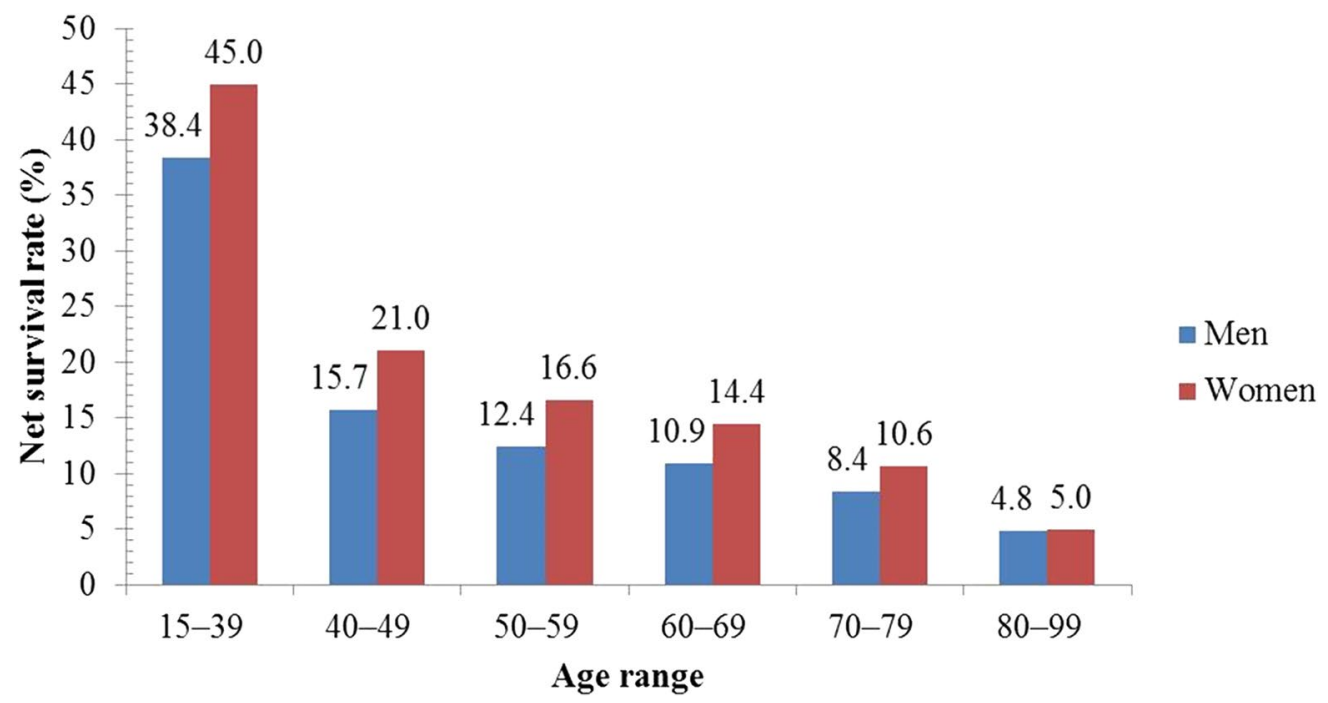

Fig. 4 Five-year net survival rate of lung cancer patients by age in the United Kingdom (UK). During the period 2007-2011, the 5-year age-standardized net survival rates of men with lung cancer gradually decreased from $38.4 \%$ to $4.8 \%$; for women, it decreased from $45.0 \%$ to $5.0 \%$. This shows that the 5-year survival for lung cancer is highest in the youngest men and women and decreases with increasing age

\section{Lung cancer epidemiology in the US}

Next, we examined lung cancer incidence and mortality in the US during the period 1975-2014 [29-31]. As with the data from the UK, the lung cancer data from the US were analyzed considering the age-adjusted or age-standardized rates, and SEER database incidences. For men, the lung cancer incidence increased during 1975-1980 and then gradually decreased during the period 19852014 (Table 2). However, mortality gradually increased during 1975-1990 and decreased moderately during 1995-2014 (Table 3). For women, the incidence of lung cancer slowly increased during 1975-2005, whereas the mortality first increased gradually during 1975-2000 and sharply thereafter.

Figure 5 shows the 1-year survival rates [32]. For men and women in the US, the 1-year lung cancer survival rate increased from $33.4 \%$ to $40.7 \%$ and from $40.4 \%$ to $48.5 \%$, respectively, over the period 1975-2010. Figure 6 
Table 2 Age-adjusted rate of lung cancer incidence in the United States (1975-2014)

\begin{tabular}{|c|c|c|c|c|c|c|c|c|c|}
\hline \multirow[t]{2}{*}{ Year } & \multicolumn{3}{|c|}{ All races (per 100,000 people) } & \multicolumn{3}{|c|}{ Whites (per 100,000 people) } & \multicolumn{3}{|c|}{ Blacks (per 100,000 people) } \\
\hline & Both sexes & Men & Women & Both sexes & Men & Women & Both sexes & Men & Women \\
\hline 1975 & 52.2 & 89.5 & 24.5 & 51.9 & 89.1 & 24.8 & 64.5 & 114.9 & 24.7 \\
\hline 1980 & 60.7 & 99.9 & 32.2 & 59.4 & 97.7 & 32.3 & 86.6 & 151.3 & 38.2 \\
\hline 1985 & 64.6 & 98.6 & 40.2 & 63.9 & 96.9 & 40.9 & 89.6 & 149.7 & 46.0 \\
\hline 1990 & 68.0 & 96.9 & 47.8 & 68.2 & 96.1 & 48.9 & 86.8 & 137.1 & 52.1 \\
\hline 1995 & 66.8 & 89.8 & 50.4 & 67.1 & 87.9 & 52.4 & 85.8 & 138.7 & 50.0 \\
\hline 2000 & 64.1 & 82.1 & 51.2 & 64.6 & 80.8 & 53.2 & 80.1 & 114.2 & 57.3 \\
\hline 2005 & 62.9 & 75.7 & 53.7 & 63.9 & 75.5 & 55.7 & 74.4 & 97.7 & 59.2 \\
\hline 2010 & 57.2 & 67.5 & 49.7 & 58.4 & 67.2 & 51.8 & 66.2 & 85.0 & 53.9 \\
\hline $2011-2014$ & 55.5 & 64.8 & 48.6 & 56.4 & 64.4 & 50.7 & 64.6 & 85.3 & 51.0 \\
\hline
\end{tabular}

Table 3 Age-adjusted rate of lung cancer mortality in the United States (1975-2014)

\begin{tabular}{|c|c|c|c|c|c|c|c|c|c|}
\hline \multirow[t]{2}{*}{ Year } & \multicolumn{3}{|c|}{ All races (per 100,000 people) } & \multicolumn{3}{|c|}{ Whites (per 100,000 people) } & \multicolumn{3}{|c|}{ Blacks (per 100,000 people) } \\
\hline & Both sexes & Men & Women & Both sexes & Men & Women & Both sexes & Men & Women \\
\hline 1975 & 42.6 & 76.3 & 17.5 & 42.0 & 75.4 & 17.6 & 49.3 & 91.0 & 17.3 \\
\hline 1980 & 49.4 & 84.7 & 24.1 & 48.7 & 83.2 & 24.2 & 59.1 & 106.6 & 24.5 \\
\hline 1985 & 54.3 & 88.5 & 30.4 & 53.6 & 86.6 & 30.8 & 65.7 & 117.5 & 29.6 \\
\hline 1990 & 58.8 & 90.5 & 36.8 & 58.1 & 88.4 & 37.3 & 72.0 & 125.1 & 36.4 \\
\hline 1995 & 58.3 & 84.3 & 40.2 & 58.0 & 82.6 & 40.9 & 69.2 & 116.0 & 38.8 \\
\hline 2000 & 55.8 & 76.4 & 41.1 & 55.9 & 75.4 & 42.0 & 63.7 & 100.8 & 39.6 \\
\hline 2005 & 52.8 & 69.4 & 40.7 & 53.3 & 69.0 & 41.7 & 58.5 & 86.9 & 40.1 \\
\hline 2010 & 47.4 & 60.0 & 37.9 & 48.1 & 59.9 & 39.1 & 51.1 & 73.5 & 36.2 \\
\hline $2011-2014$ & 46.0 & 57.8 & 37.0 & 46.7 & 57.8 & 38.1 & 49.3 & 70.0 & 35.4 \\
\hline
\end{tabular}

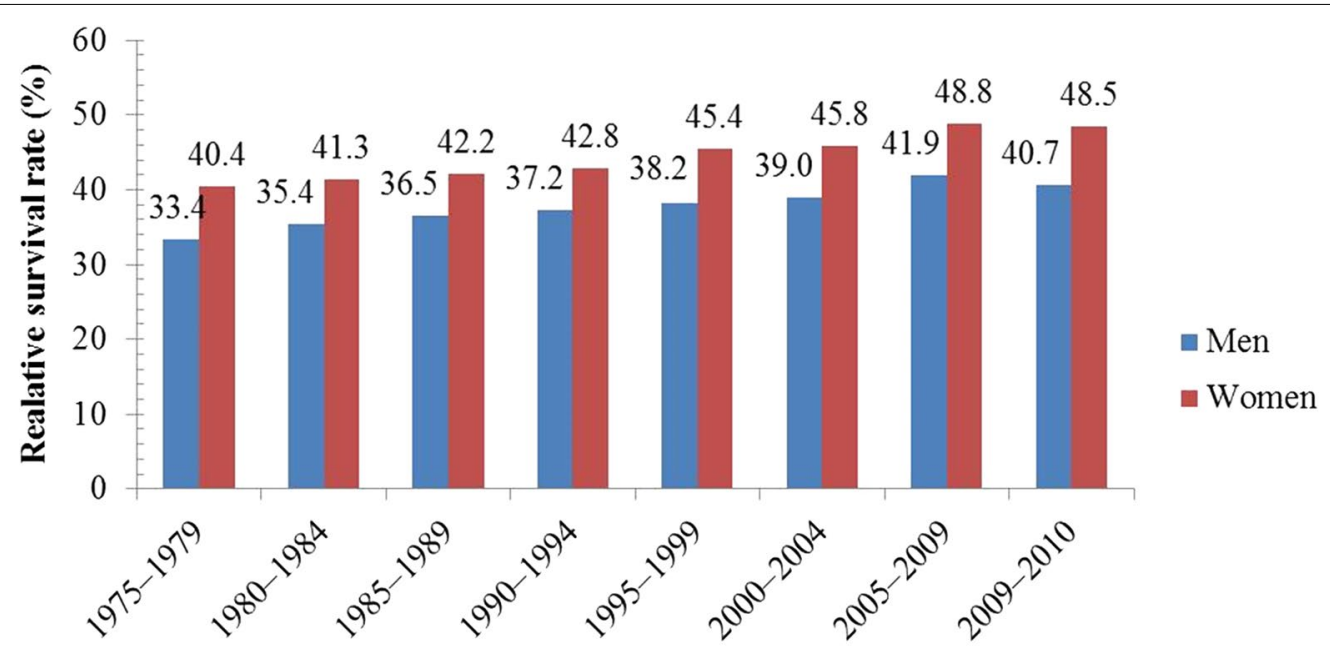

Period of diagnosis

Fig. 5 One-year relative survival trends of lung cancer patients in the United States (US). During the period 1975-2010, 1-year relative survival rate for men with lung cancer increased from $33.4 \%$ to $40.7 \%$; for women, it increased from $40.4 \%$ to $48.5 \%$ 


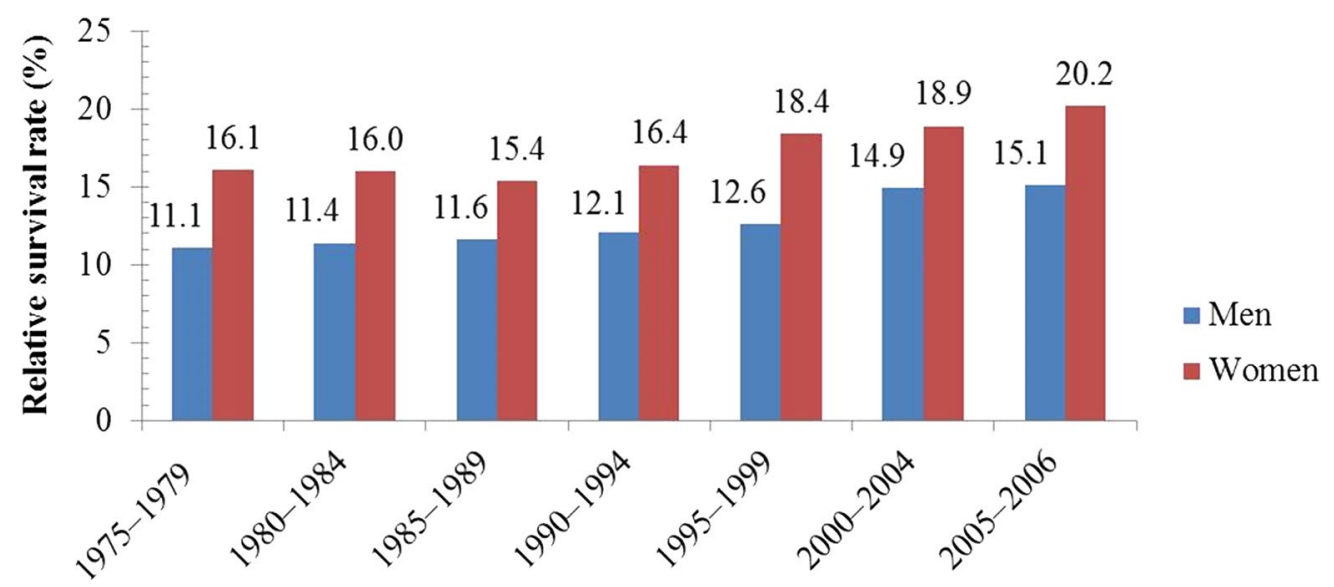

Period of diagnosis

Fig. 6 Five-year relative survival trends of lung cancer patients over time in the US. The 5 -year relative survival rate of men with lung cancer increased from $11.1 \%$ to $15.1 \%$; for women, it increased from $16.1 \%$ to $20.2 \%$

shows that in the US, the 5-year survival rate of male and female lung cancer patients increased from $11.1 \%$ to $15.1 \%$ and from $16.1 \%$ to $20.2 \%$, respectively, during the period 1975-2006. In the year 2012, approximately 402,326 Americans had lung cancer [32]. The CDC estimated 221,220 new cases of lung cancer in 2015, representing $13.0 \%$ of all diagnosed cases of cancer [30]. Some studies showed that the chances of a person developing lung cancer depend on many factors, such as past or current smoking status, age, and sex [32]. Male smokers were at 23-times higher risk of lung cancer than male non-smokers; similarly, female smokers were at 13-times higher risk of lung cancer than female non-smokers [33].

As shown in Table 4, a 60-year-old man has a probability of $1.9 \%$ of developing lung cancer over the next 10 years; the corresponding probability for a 60 -year-old woman is only $1.5 \%$ [34].

\section{Lung cancer epidemiology in India and Egypt}

Further, we examined lung cancer incidence and mortality in India during the period 1980-2014 considering the age-standardized rate (Table 5) $[2,7,35,36]$. The availability of these data from India was limited. The incidence of lung cancer for both men and women increased during 1980-2014.

Finally, we examined lung cancer incidence and mortality in Egypt during the period 2000-2014. As in India, lung cancer incidence and mortality data were scarce in Egypt. Table 6 compiles the available data [2, 7, 37-39]. In Egypt, the mortality of lung cancer increased between 2000 and 2014; smoking was the main risk factor of lung cancer in Egyptians also [7, 37-39].
In the present study, we reviewed approximately 110 articles published by Elsevier, IEEE, and Springer during the period 2007-2015. We found that data mining and evolutionary algorithms were capable in efficiently classifying lung cancer data as depicted in Fig. 7. Previously, data mining methods were used alone by many researchers; however, our study indicated that the combination of data mining and evolutionary algorithms were more effective for the detection of lung cancer.

\section{Discussion}

We found that currently the incidence and mortality patterns of lung cancer closely follow each other at the global level. In the US and the UK, advanced technology and awareness programs have helped decrease the mortality from lung cancer; however, this is not the case in India and Egypt, where more effective steps, such as development of special awareness programs, are required to decrease lung cancer mortality.

Cancer epidemiology is the study of causes and risk factors of a cancer for a given population. It can be helpful by allowing (i) the identification of health problems related to cancer, (ii) the measurement of the spread of the disease in a community, (iii) the expansion of knowledge about the risk factors of cancer, and (iv) a better understanding of the effects of cancer.

Cancer epidemiology can provide insights into the causes of cancer. However, the area under an epidemiologic investigation is often limited to a particular region and usually involves a small sample size. Since cancer epidemiology is analytical in nature, additional computational methods are required. Sample size can be 
Table 4 Estimated probability of developing lung cancer in men and women in the United States 10, 20, and 30 years later according to their current ages (2010-2012)

\begin{tabular}{|c|c|c|c|c|c|c|}
\hline \multirow[t]{3}{*}{ Current age (years) } & \multicolumn{6}{|c|}{ Lung cancer risk (\%) } \\
\hline & \multicolumn{2}{|c|}{10 years } & \multicolumn{2}{|c|}{20 years } & \multicolumn{2}{|c|}{30 years } \\
\hline & Men & Women & Men & Women & Men & Women \\
\hline 30 & 0.0 & 0.0 & 0.1 & 0.1 & 0.8 & 0.7 \\
\hline 40 & 0.1 & 0.1 & 0.8 & 0.7 & 2.5 & 2.1 \\
\hline 50 & 0.6 & 0.5 & 2.5 & 2.0 & 5.3 & 4.2 \\
\hline 60 & 1.9 & 1.5 & 5.0 & 3.8 & 7.0 & 5.4 \\
\hline 70 & 3.5 & 2.6 & 5.9 & 4.4 & NA & NA \\
\hline
\end{tabular}

NA Not available

Table 5 Age-adjusted rates of lung cancer incidence and mortality in India (1980-2014)

\begin{tabular}{llllll}
\hline Year & \multicolumn{2}{l}{$\begin{array}{l}\text { Incidence (per 100,000 } \\
\text { people) }\end{array}$} & & \multicolumn{2}{l}{$\begin{array}{l}\text { Mortality (per } \\
\text { 100,000 people) }\end{array}$} \\
\cline { 2 - 3 } \cline { 5 - 6 } & Men & Women & & Men & Women \\
\hline 1980 & 11.6 & 1.8 & & NA & NA \\
1985 & 11.2 & 1.3 & & NA & NA \\
1990 & 14.1 & 3.0 & & NA & NA \\
1995 & 13.0 & 3.7 & & NA & NA \\
2000 & 10.0 & 4.2 & & NA & NA \\
2005 & 10.7 & 5.0 & & NA & NA \\
2010 & 47.1 & 11.4 & & 41.3 & 9.7 \\
$2011-2014$ & 53.7 & 16.5 & & 48.6 & 15.0 \\
\hline
\end{tabular}

NA Not available

Table 6 Age-adjusted rates of lung cancer incidence and mortality in Egypt (2000-2014)

\begin{tabular}{llllll}
\hline Year & \multicolumn{2}{l}{$\begin{array}{l}l \\
\text { Incidence (per 100,000 } \\
\text { people) }\end{array}$} & & \multicolumn{2}{l}{$\begin{array}{l}\text { Mortality (per } \\
\mathbf{1 0 0 , 0 0 0} \text { people) }\end{array}$} \\
\cline { 2 - 3 } \cline { 5 - 6 } & Men & Women & & Men & Women \\
\hline 2000 & 11.9 & 3.7 & & NA & NA \\
2005 & 14.0 & 3.0 & & NA & NA \\
2010 & 9.6 & 2.5 & & 9.1 & 2.3 \\
$2011-2014$ & 36.3 & 13.8 & & 32.4 & 12.4 \\
\hline
\end{tabular}

NA Not available

increased easily, which can yield better classification results.

Data mining techniques can provide better classification and categorization of data, but these techniques may not efficiently cluster, classify, and predict the trends of sequential and time series data; hence, evolutionary algorithms are used to obtain optimal solutions in such cases. Evolutionary algorithms can produce high-quality analytical solutions and can simplify the problems during different iterative stages. Evolutionary algorithms such as ant colony optimization (ACO), particle swarm optimization (PSO), and artificial bee colony (ABC) are beneficial as these algorithms are capable of achieving a nearer solution in comparison to that achieved by the use of data mining techniques alone.

Pattern finding is very important in cancer detection. For this, data mining methods are needed. Data mining is a procedure by which pertinent patterns can be separated from large databases [40]. According to Jain et al. [41], data mining can be used for six specific tasks: classification, estimation, prediction, association rule mining, clustering, and visualization. Classification, estimation, and prediction are examples of supervised learning. The primary aim of these techniques is to prepare a model based on the available data, which can represent one or more attributes. Association rule mining, clustering, and visualization are examples of unsupervised learning. The primary aim of these techniques is to establish relationships between attributes. The six methods are used in nearly every area of healthcare databases for knowledge discovery, classification, and prediction. Of them, association rule mining, classification, and clustering are the most commonly used data mining techniques. These methods may provide a real solution for discovering similar types of groups, group patterns, the frequency of items present in the groups, the extraction of significant patterns, and pattern visualization [42]. Since lung cancer symptoms are not the same in every patient, it is essential to characterize their distinctive features and give unique treatments to different patients. In this regard, clustering or classification techniques may be useful because several factors, such as age, sex, genetics, alcohol consumption, smoking status, and weight may contribute to lung cancer.

According to Dass et al. [43], the two most important factors in cancer treatment are classification and characterization. They successfully achieved all the classification rules by using Apriori algorithm, which is helpful in 


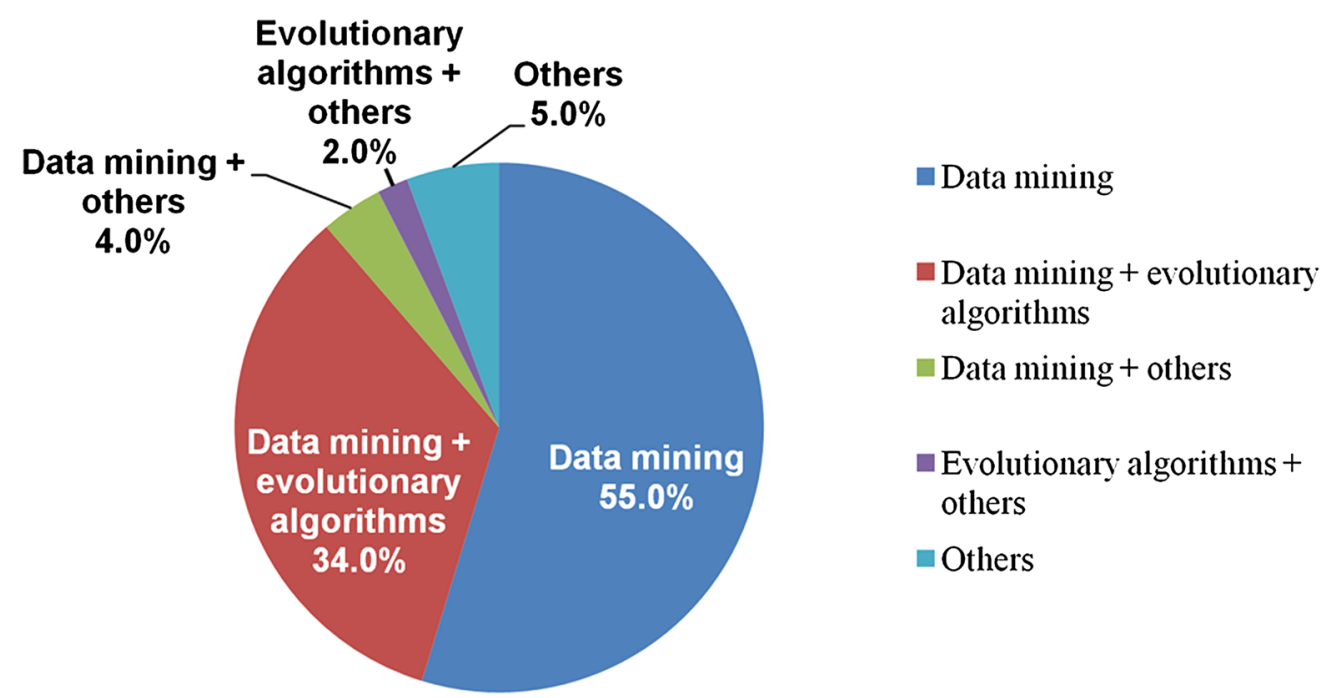

Fig. 7 Percentage of different methods used in lung cancer diagnosis. It shows the frequency of data mining methods and evolutionary algorithms used for lung cancer diagnosis, as reported in references [43-70]

the diagnosis of and the drug development for squamous cell cancer (SCC) and adenocarcinoma (ADC) [43]. Rajan et al. [44] suggested that the early diagnosis of lung cancer is mainly dependent on its historical data. Using association rule mining, Agrawal et al. [45] identified hotspots in lung cancer SEER data. A prototype mortality risk calculator was developed in this study; and the obtained rules satisfied biomedical knowledge. According to Yadav et al. [46], the detection of lung cancer is difficult at an early stage because it depends on multiple attributes. They used clustering approach for analyzing dataset from Sanjay Gandhi Post Graduate Institute of Medical Science, Lucknow, India. They compared the traditional clustering with foggy clustering method and achieved better results by using the latter. Piedra et al. [47] suggested text mining for a better understanding of the diagnostic process, classification accuracy, and disease facts; this can also be helpful in predictive model design, alert system, and decision-making process. Nahar et al. [48] used the association rule mining for identifying risk factors in different types of cancer. For this, they used three different types of association rule mining algorithms: the Apriori, predictive Apriori, and tertius algorithms. The Apriori algorithm outperforms the other algorithms. According to Wang et al. [49], Bayesian network is a very useful method for understanding cancer metastasis. The study included 50,000 cancer patients from Taiwan, China, between 1996 and 2010. Sensitivity and specificity measures were compared based on three different approaches, namely naive Bayes, logistic regression, and support vector machine (SVM), but the researchers did not find significant differences in terms of accuracy and specificity of the results. The interpretation capabilities of naive Bayes were superior to those of the other approaches, and it was also efficient in cases of missing information, modeling of non-linear situations, and stochastic medical problems. In their study, Krishnaiah et al. [50] examined decision tree, naive Bayes, and artificial neural network. One dependency-augmented naive Bayes classifier and one naive creedal classifier 2 were used for data preprocessing and decision making purposes, and the prediction results were better than the traditional methods. According to Phillips-Wren et al. [51], when decision tree and artificial neural network were used in combination, the chances of good prediction results became high. Debnath et al. [52] proposed a new evolutionary method for efficient classification of lung cancer genes. When a smaller number of genes were selected, this method provided better classification accuracy. According to Esfandiari et al. [53], data mining can determine the frequency of the task at a specified time. According to their study, data mining can be applied for disease prediction by data pre-processing and data modeling. Balachandran et al. [54] performed data mining to conduct a systematic study of lung cancer. The data were collected from medically confirmed and diagnosed patients. Their results showed that training-based approaches such as neural network performed better than cross-validation approaches. Fung et al. [55] proposed a new classifier that combined the impact factors (IFs) method and Golub and Slonim (GS) method with k-nearest neighbour (KNN). They achieved good classification performance for lung and prostate cancer data. Kushwah et al. [56] used neural network with random forest tree classifier for cancer 
gene selection. According to their results, classification capability could be increased with the help of trained neural networks. Guo et al. [57] used a network-based method on 164 smokers to identify the genes associated with smoking. They identified genes associated with lung cancer survival and genes that could distinguish smokers and non-smokers; the accuracy of the method was $73.0 \%$. Ahmed et al. [58] prepared a database of 400 patients that comprised patients with or without cancer. For pre-processing, k-means clustering was used. The results proved that this method was efficient in lung cancer risk identification. Sun et al. [59] suggested that the SVM can be used for lung cancer classification, based on the comparison of different algorithms, such as boosting, decision tree, and KNN. Oztekin et al. [60] proposed a prediction model based on decision tree, neural network, and logistic regression. The study suggested that these algorithms were capable of accurate classification of the lung cancer dataset.

Evolutionary algorithms are population-based metaheuristic optimization algorithms that are inspired by nature. The principal evolutionary algorithms are genetic algorithm (GA), ACO, PSO, ABC, and memetic algorithm. Now, evolutionary algorithms, in combination with the previously discussed methodologies, are being discussed. These algorithms can locate the closest solution even when dealing with complex issues.

Li et al. [61] proposed a bionic enhancement calculation-based system, termed ant colony optimizationselection (ACO-S) for high-dimensional datasets. The outcomes demonstrated that ACO-S could produce a high-quality subset with a small size and better characterization. Yu et al. [62] recommended ACO sampling to address the issue of class unevenness. The methodology resulted in greater grounded speculation capacity as compared with the traditional methods. Sowmiya et al. [63] suggested neural network and fuzzy logic to train data. Then, by using ACO, classification accuracy was improved. Alba et al. [64] compared PSO and GA. They used SVM in combination with either of the algorithms on high-dimensional microarray data for classification. The combination of PSO and SVM was capable of finding interesting genes. Minimum redundancy maximum relevance (MRMR)-GA was compared with GA-SVM wrapper and MRMR filter. In terms of selection and classification performance, MRMR-GA produced better results. Qasem et al. [65] presented a new multi-objective algorithm based on swarm optimization for classification problems, termed multi-objective particle swarm optimization RBF network (MPSON). The results indicated that this method had good generalization capability along with compact network structure. Runkler et al. [66] made efforts to minimize fuzzy c-means model using
ACO, alternate optimization (AO), and PSO. They suggested two different forms of PSO: the first was PSO-V for representing particle as a component of a cluster center; the second was PSO-U for representing particle as a non-scaled and non-normalized membership value. $\mathrm{PSO}-\mathrm{V}$ and $\mathrm{PSO}-\mathrm{U}$ were compared with $\mathrm{AO}$ and $\mathrm{ACO}$. They were compared with two different datasets: single outlier and lung cancer. The results of ACO, PSO-V, and PSO-U were slower than AO, but PSO variants outperformed significantly after each round of iteration. Liu et al. [67] suggested discrete particle swarm optimization (DPSO) and rule pruning for lung cancer diagnosis and achieved $68.3 \%$ classification accuracy. Liu et al. [68] used the PSO-based simultaneous learning framework for clustering and classification (PSOSLCC). PSOSLCC was applied to a real-world application, namely texture image segmentation, and good performance was obtained, showing that it could potentially classify problems on a large scale. Chen et al. [69] proposed an approach based on PSO with a decision tree classifier for statistical analysis. They found that this method outperformed other popular classifiers (i.e., SVM, self-organizing map, back propagation neural network, and C4.5 decision tree) by conducting experiments on 11 gene expression cancer datasets. Subbulakshmi et al. [70] proposed an efficient hybrid approach based on PSO with an extreme learning machine classifier. It had self-regulated learning capability that showed good generalization performance. These studies above suggested that the data mining and evolutionary algorithms both are efficient in lung cancer detection; while the evolutionary algorithms have the capabilities of handling complex problems, the data mining algorithms alone may fail. Therefore, combining both approaches at different levels of classification and clustering may produce better outcomes.

The use of tobacco products causes approximately 5 million deaths worldwide annually, with 2.41 million deaths in developing countries and 2.43 million deaths in developed countries [71-73]. Of the 5 million deaths that occurred annually in India, approximately 1 million could be attributed to cancer [71, 74]; by 2020, this figure is estimated to reach 1.5 million [40]. Smoking is responsible for $80.0 \%$ of the lung cancer incidences worldwide [71-74]. In India, cigarette or beedi smoking causes the majority of the deaths in the 25-69 age group [71, 75]. Some studies have reported that $15.0 \%$ of lung cancer cases were caused by genetic factors, air pollution, or exposure to radon gas, asbestos, and pesticides [71, 76, 77]. These studies also showed that, Indian non-smokers have almost the same chance of getting lung cancer as smokers because of exposure to pesticides and other carcinogens (Fig. 8) [36, 77]. Our results suggest that there must be strict restrictions on the use of tobacco products. 


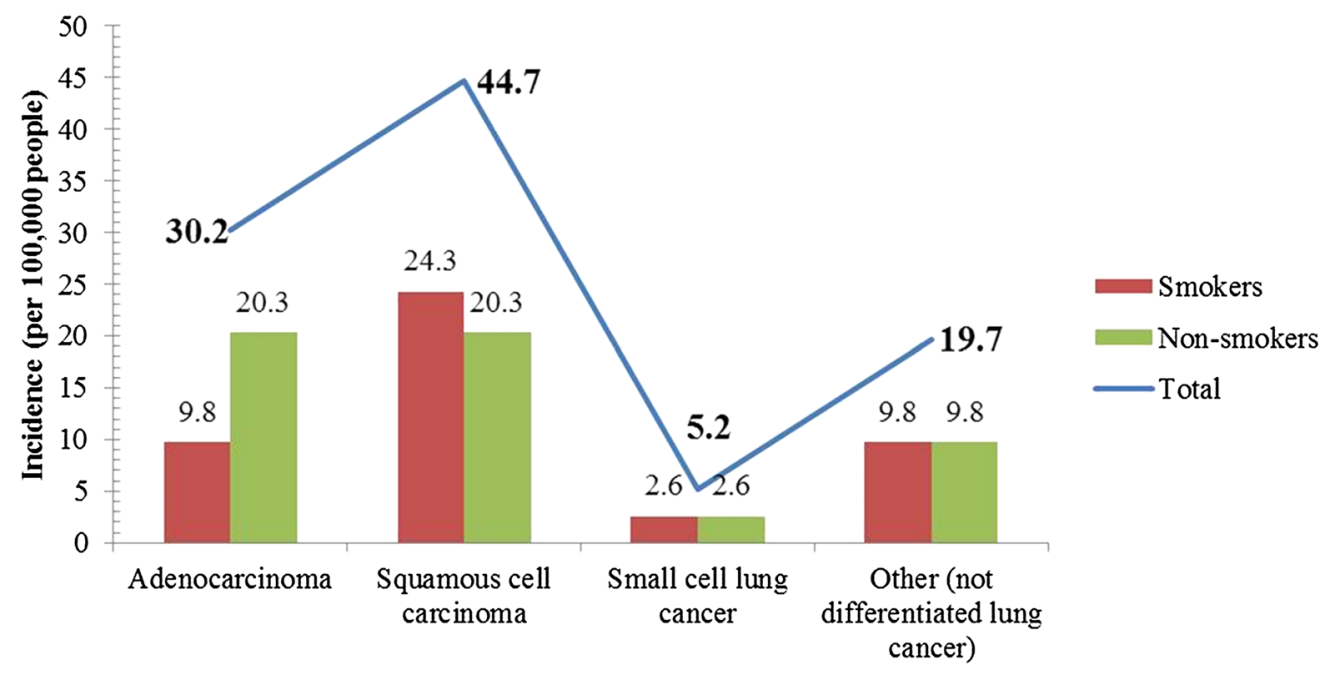

Fig. 8 Relationship of the incidence of various histological types of lung cancer with smoking in India

\section{Study limitations and future directions}

This study has some limitations. Firstly, maximum collection of data was based on the continuous availability of data, but in some cases the data were from one-time community- or hospital-based surveys. The incidence and mortality data from India and Egypt may not be complete. Therefore, deviations in incidence and mortality from the actual are possible. However, these errors may be negligible, since as much data as possible were taken from identified sources and published papers. Secondly, we considered lung cancer statistics only from the UK, the US, India, and Egypt. The results will vary if more countries are considered. Thirdly, further research is required to clarify how data mining and evolutionary algorithms can be used together, and which combined techniques will be most effective. Finally, only Englishlanguage sources and publications were examined.

\section{Conclusions}

In developed countries, such as the UK and the US, lung cancer mortality is declining and a high survival rate has been achieved, likely due to awareness programs and advanced medical technologies. However, in developing countries such as India and Egypt, substantial efforts are need to decrease cancer mortality.

We also analyzed computational methodologies for their usefulness in the early detection of lung cancer. It was found that data mining techniques such as classification, clustering, and association rule mining were most commonly used but a better outcome could be achieved if data mining is combined with the evolutionary algorithms. We also found that when lung cancer symptoms were identified correctly, the chances of detection increased; and for this classification, clustering techniques of data mining could be employed. The chances of getting good results are lower with a single method, since the characteristics of lung cancer may be different. Data mining along with evolutionary algorithms can better characterize lung cancer symptoms at different levels, arrange them in groups, and determine rankings to allow their stage and behavior being identified correctly and timely.

\section{Authors' contributions}

AKD developed the research plan. AKD and UG retrieved the data and performed the analysis. AKD and UG developed the analysis of the methods. AKD, UG, and SJ conceived the study and participated in its design and coordination. AKD revised the manuscript and assisted with formatting and language editing. All authors read and approved the final manuscript.

\section{Acknowledgements}

The authors thank Dr. Vijoy Jha, Department of Nephrology, All India Institute of Medical Sciences (AllMS), New Delhi, India, and Dr. Feroz Khan, Editorin-Chief, Sci-Edit Publications, San Francisco, CA, USA, for their assistance in preparing and amending this manuscript.

\section{Competing interests \\ The authors declare that they have no competing interests.}

Received: 24 July 2015 Accepted: 21 July 2016

Published online: 30 July 2016

\section{References}

1. Fan Z, Ji T, Wan S, Wu Y, Zhu Y, Xiao F, et al. Smoking and risk of meningioma: a meta-analysis. Cancer Epidemiol. 2013;37(1):39-45.

2. Ferlay J, Soerjomataram I, Dikshit R, Eser S, Mathers C, Rebelo M, et al. Cancer incidence and mortality worldwide: sources, methods and major patterns in GLOBOCAN 2012. Int J Cancer. 2015;136(5):E359-86.

3. Dubey AK, Gupta U, Jain S. Breast cancer statistics and prediction methodology: a systematic review and analysis. Asian Pac J Cancer Prev. 2015;16(10):4237-45. 
4. Parkin DM, Bray F, Ferlay J, Pisani P. Estimating the world cancer burden: GLOBOCAN 2000. Int J Cancer. 2001;94(2):153-6.

5. Ramadas K, Sauvaget C, Thomas G, Fayette JM, Thara S, Sankaranarayanan R. Effect of tobacco chewing, tobacco smoking and alcohol on all-cause and cancer mortality: a cohort study from Trivandrum, India. Cancer Epidemiol. 2010;34(4):405-12.

6. Ali I, Wani WA, Saleem K. Cancer scenario in India with future perspectives. Cancer Ther. 2011;8(1):56-70.

7. Stewart BW, Kleihues P, editors. World cancer report. Lyon: IARC press; 2003.

8. De Martel C, Ferlay J, Franceschi S, Vignat J, Bray F, Forman D, et al. Global burden of cancers attributable to infections in 2008: a review and synthetic analysis. Lancet Oncol. 2012;13(6):607-15.

9. Rothman KJ, Greenland S, Lash TL, editors. Modern epidemiology. Philadelphia: Lippincott Williams \& Wilkins; 2008.

10. Nelson KE, Williams CM. Infectious disease epidemiology: theory and practice. Burlington: Jones \& Bartlett Publishers; 2014

11. Huang B, Guo J, Charnigo R. Statistical methods for population-based cancer survival in registry data. J Biom Biostat. 2014;5:e129.

12. Parkin DM, Hakulinen T. Analysis of survival. Cancer registration. Principles and methods. IARC Sci Publ. 1991;95:159-76.

13. Office for National Statistics. Cancer statistics: registrations series MB1. http://www.ons.gov.uk/ons/search/index.html?newquery=series $+\mathrm{mb} 1$. Accessed 20 Dec 2014.

14. Welsh Cancer Intelligence and Surveillance Unit. http://www.wcisu.wales. nhs.uk. Accessed 20 Dec 2014

15. Forman D. Cancer incidence and survival by major ethnic group, England, 2002-2006. National cancer intelligence network. 2009. http://www.ncin. org.uk/home. Accessed 15 Jan 2015.

16. Information Services Division Scotland. Cancer information program. http://www.isdscotland.org/cancer. Accessed 15 Jan 2014

17. Northern Ireland Cancer Registry. http://www.qub.ac.uk/nicr. Accessed 15 Jan 2014.

18. General Register Office for Scotland, Deaths Time Series Data, Deaths in Scotland. http://www.gro-scotland.gov.uk/statistics/theme/vital-events/ deaths/time-series.html. Accessed 15 Jan 2015.

19. Northern Ireland Statistics and Research Agency, Deaths by cause. http:// www.nisra.gov.uk/demography/default.asp14.htm. Accessed $28 \mathrm{Mar}$ 2015.

20. Parkin DM. 1. The fraction of cancer attributable to lifestyle and environmental factors in the UK in 2010. Br J Cancer. 2011;105:S2-5.

21. Cogliano VJ, Baan R, Straif K, Grosse Y, Lauby-Secretan B, El Ghissassi F, et al. Preventable exposures associated with human cancers. J Natl Cancer Inst. 2011;103(24):1827-39.

22. Flanders WD, Lally CA, Zhu BP, Henley SJ, Thun MJ. Lung cancer mortality in relation to age, duration of smoking, and daily cigarette consumption results from cancer prevention study II. Cancer Res. 2003;63(19):6556-62.

23. Parkin DM. 2. Tobacco-attributable cancer burden in the UK in 2010. Br J Cancer. 2011:105:56-13.

24. Lubin JH, Caporaso NE. Cigarette smoking and lung cancer: modeling total exposure and intensity. Cancer Epidemiol Biomarkers Prev. 2006;15(3):517-23.

25. Quaresma M, Coleman MP, Rachet B. 40-year trends in an index of survival for all cancers combined and survival adjusted for age and sex for each cancer in England and Wales, 1971-2011: a population-based study. Lancet. 2015;385(9974):1206-18.

26. United Kingdom and Ireland Association of Cancer Registries (UKIACR). 2011. http://www.ukiacr.org. Accessed 28 Mar 2015.

27. Coleman MP, Forman D, Bryant $\mathrm{H}$, Butler J, Rachet B, Maringe C, et al. Cancer survival in Australia, Canada, Denmark, Norway, Sweden, and the UK, 1995-2007 (the international cancer benchmarking partnership): an analysis of population-based cancer registry data. Lancet. 2011;377(9760):127-38.

28. Berrino F, De Angelis R, Sant M, Rosso S, Lasota MB, Coebergh JW, et al. Survival for eight major cancers and all cancers combined for European adults diagnosed in 1995-99: results of the EUROCARE-4 study. Lancet Oncol. 2007:8(9):773-83.

29. US National Institutes of Health. National Cancer Institute, DCCPS, Surveillance Research Program, Cancer Statistics Branch. Surveillance, Epidemiology, and End Results (SEER). Program Research Data (1973-2008). http://www.seer.cancer.gov. Accessed 28 Mar 2015.
30. Centers for Disease Control and Prevention. http://www.cdc.gov/about/ default.htm. Accessed 20 Mar 2015

31. Ferlay J, Shin HR, Bray F, Forman D, Mathers C, Parkin DM. Estimates of worldwide burden of cancer in 2008: GLOBOCAN 2008. Int J Cancer. 2010;127(12):2893-917.

32. Altekruse SF, Kosary CL, Krapcho M. National Cancer Institute. SEER cancer statistics review, 1975-2007. http://seer.cancer.gov. Accessed 30 Mar 2015.

33. US Department of Health and Human Services. The health consequences of smoking: a report of the surgeon general. Atlanta, GA: US Department of Health and Human Services, Centers for Disease Control and Prevention, National Center for Chronic Disease Prevention and Health Promotion, Office on Smoking and Health. CDC, US. 2004; 62.

34. Howlader N, Noone AM, Krapcho M, Neyman N, Aminou R, Waldron W, et al. SEER cancer statistics review, 1975-2012. Bethesda: National Cancer Institute; 2011. p. 19.

35. Behera D, Balamugesh T. Lung cancer in India. Indian J Chest Dis Allied Sci. 2004:46:269-82

36. Lung Cancer Focus: India. http://www.siroclinpharm.com. Accessed 22 Apr 2015.

37. Larbi ABID. AMAAC Workshop, Algiers. 2011.

38. Freedman $L S$, Edwards BK, Ries LAG, Young JL. Cancer incidence in four member countries (Cyprus, Egypt, Israel, and Jordan) of the Middle East cancer consortium (MECC) compared with US SEER. 2006.

39. Curado MP, Edwards B, Shin HR, Storm H, Ferlay J, Heanue M, et al. Cancer incidence in five continents, vol. IX. Lyon: IARC; 2007.

40. Agrawal R, Srikant R. Fast algorithms for mining association rules. In: Proceedings of 20th international conference on very large data bases, VLDB. 1994; 1215: 487-99.

41. Jain R. Introduction to data mining techniques. http://www.iasri.res.in/ ebook/expertsystem/datamining.pdf. Accessed 22 Apr 2015.

42. Khaing HW. Data mining based fragmentation and prediction of medical data. In: Third international conference on computer research and development (ICCRD), IEEE. 2011;2: 480-85.

43. Dass MV, Rasheed MA, Ali MM. Classification of lung cancer subtypes by data mining technique. In: international conference on control, instrumentation, energy and communication (CIEC), IEEE. 2014; 558-562.

44. Rajan JR, Chelvan CC. A survey on mining techniques for early lung cancer diagnoses. In: International conference on green computing, communication and conservation of energy (ICGCE), IEEE. 2013; 918-22.

45. Agrawal A, Misra S, Narayanan R, Polepeddi L, Choudhary A. "Poster: a lung cancer mortality risk calculator based on SEER data. In: First international conference on computational advances in bio and medical sciences (ICCABS), IEEE. 2011:233.

46. Yadav AK, Tomar D, Agarwal S. Clustering of lung cancer data using foggy k-means. In: International conference on recent trends in information technology (ICRTIT), IEEE. 2013; 13-8.

47. Piedra D, Ferrer A, Gea J. Text mining and medicine: usefulness in respiratory diseases. Arch Bronconeumol (Engl Edn). 2014;50(3):113-9.

48. Nahar J, Tickle KS. Significant cancer risk factor extraction: an association rule discovery approach. In: International conference on computer and information technology (ICCIT), IEEE. 2008; 108-114.

49. Wang KJ, Makond B, Wang KM. Modeling and predicting the occurrence of brain metastasis from lung cancer by Bayesian network: a case study of Taiwan. Comput Biol Med. 2014:47:147-60.

50. Krishnaiah V, Narsimha DG, Chandra DNS. Diagnosis of lung cancer prediction system using data mining classification techniques. Int J Comput Sci Inf Technol Adv Res. 2013;4(1):39-45.

51. Phillips-Wren G, Sharkey P, Dy SM. Mining lung cancer patient data to assess healthcare resource utilization. Expert Syst Appl. 2008;35(4):1611-9.

52. Debnath R, Kurita T. An evolutionary approach for gene selection and classification of microarray data based on SVM error-bound theories. Biosystems. 2010;100(1):39-46.

53. Esfandiari N, Babavalian MR, Moghadam AME, Tabar VK. Knowledge discovery in medicine: current issue and future trend. Expert Syst Appl. 2014;41(9):4434-63.

54. Balachandran K, Anitha R. Ensemble based optimal classification model for pre-diagnosis of lung cancer. In: Fourth international conference on computing, communications and networking technologies (ICCCNT), IEEE. 2013; 1-7. 
55. Fung BY, Ng VT. Improving classification performance for heterogeneous cancer gene expression data. In: International conference on information technology: coding and computing, IEEE. 2004; 2: 131-122.

56. Kushwah J, Singh D. Classification of cancer gene selection using random forest and neural network based ensemble classifier. Int J Adv Comput Res. 2013;3(2):30-4.

57. Guo NL, Wan YW. Pathway-based identification of a smoking associated 6-gene signature predictive of lung cancer risk and survival. Artif Intell Med. 2012;55(2):97-105

58. Ahmed K, Abdullah-Al-Emran AAE, Jesmin T, Mukti RF, Rahman M, Ahmed F. Early detection of lung cancer risk using data mining. Asian Pac J Cancer Prev. 2013;14(1):595-8.

59. Sun T, Wang J, Li X, Lv P, Liu F, Luo Y, et al. Comparative evaluation of support vector machines for computer aided diagnosis of lung cancer in CT based on a multi-dimensional data set. Comput Methods Programs Biomed. 2013;111(2):519-24.

60. Oztekin A, Delen D, Kong ZJ. Predicting the graft survival for heart-lung transplantation patients: an integrated data mining methodology. Int J Med Inform. 2009;78(12):e84-96.

61. Li Y, Wang G, Chen H, Shi L, Qin L. An ant colony optimization based dimension reduction method for high-dimensional datasets. J Bionic Eng. 2013:10(2):231-41.

62. Yu H, Ni J, Zhao J. ACOSampling: an ant colony optimization-based undersampling method for classifying imbalanced DNA microarray data. Neurocomputing. 2013;101:309-18.

63. Sowmiya T, Gopi M, New BM, Thomas RL. Optimization of lung cancer using modern data mining techniques. Int J Eng Res. 2014;3(5):309-14.

64. Alba E, García-Nieto J, Jourdan L,Talbi EG. Gene selection in cancer classification using PSO/SVM and GA/SVM hybrid algorithms. In: Congress of evolutionary computation, IEEE. 2007; 284-90.

65. Qasem SN, Shamsuddin SM, Hashim SZM, Darus M, Al-Shammari E. Memetic multiobjective particle swarm optimization-based radial basis function network for classification problems. Inform Sci. 2013;239:165-90.
66. Runkler T, Katz C. Fuzzy clustering by particle swarm optimization. In: International conference on fuzzy systems, IEEE. 2006: 601-8.

67. Liu Y, Chung YY. Mining cancer data with discrete particle swarm optimization and rule pruning. In: International symposium on IT in medicine and education (ITME), IEEE. 2011; 2: 31-4.

68. Liu R, Chen Y, Jiao L, Li Y. A particle swarm optimization based simultaneous learning framework for clustering and classification. Pattern Recognit. 2014:47(6):2143-52.

69. Chen KH, Wang KJ, Wang KM, Angelia MA. Applying particle swarm optimization-based decision tree classifier for cancer classification on gene expression data. Appl Soft Comput. 2014:24:773-80.

70. Subbulakshmi CV, Deepa SN. Medical dataset classification: a machine learning paradigm integrating particle swarm optimization with extreme learning machine classifier. Sci World J. 2015;2015(2015):1-12.

71. Thankappan KR, Thresia CU. Tobacco use \& social status in Kerala. Indian J Med Res. 2007;126(4):300.

72. Ezzati M. LopezAD. Estimates of global mortality attributable to smoking in 2000. Lancet. 2003:362(9387):847-52.

73. Osler M. Tobacco control in developing countries. BMJ. 2001;322(7290):869.

74. Pai SA. Gutkha banned in Indian states. Lancet Oncol. 2002;3(9):521.

75. Gajalakshmi V, Peto R, Kanaka TS, Jha P. Smoking and mortality from tuberculosis and other diseases in India: retrospective study of 43000 adult male deaths and 35000 controls. Lancet. 2003:362(9383):507-15.

76. Moore MA, Ariyaratne Y, Badar F, Bhurgri Y, Datta K, Mathew A, et al. Cancer epidemiology in South Asia-past, present and future. Asian Pac Cancer Prev. 2010;11(Suppl 2):49-66.

77. Kirmani N, Jamil K, Naidu MUR. Occupational and environmental carcinogens in epidemiology of lung cancer in South Indian population. Biol Med. 2010;2(4):1-11.

\section{Submit your next manuscript to BioMed Central and we will help you at every step:}

- We accept pre-submission inquiries

- Our selector tool helps you to find the most relevant journal

- We provide round the clock customer support

- Convenient online submission

- Thorough peer review

- Inclusion in PubMed and all major indexing services

- Maximum visibility for your research

Submit your manuscript at www.biomedcentral.com/submit 